\title{
Inhibitory Activity of Andrographolide and Andrograpanin on the Rate of $\mathrm{PGH}_{2}$ Formation
}

Sri A. Sumiwi ${ }^{1}$, Eli Halimah ${ }^{1}$, Nyi M. Saptarini ${ }^{2}$, Jutti Levita ${ }^{1}$ As'ari Nawawi ${ }^{3}$, Abdul Mutalib ${ }^{4}$, Slamet Ibrahim $^{3}$

${ }^{1}$ Department of Pharmacology and Clinical Pharmacy, Faculty of Pharmacy, Universitas Padjadjaran, Jatinangor, West Java, Indonesia

2 Department of Pharmaceutical Analysis and Medicinal Chemistry, Faculty of Pharmacy, Universitas Padjadjaran, Jatinangor, West Java, Indonesia

${ }^{3}$ School of Pharmacy, Bandung Institute of Technology, Bandung, West Java, Indonesia

${ }^{4}$ Department of Chemistry, Faculty of Mathematics and Natural Sciences, Universitas Padjadjaran, Jatinangor, West Java, Indonesia

\begin{abstract}
Cyclooxygenase (COX) or prostaglandin $\mathrm{H}_{2}$ synthase (PGHS) catalyzes the conversion of arachidonic acid into prostaglandins. Nonsteroidal anti-inflammatory drugs (NSAIDs) work by inhibiting both COX-1 and COX-2 isoforms, thus disturbing this reaction. In Indonesia, Andrographis paniculata (local name: sambiloto), is empirically used to reduce inflammation by consuming the herb tea of this plant. This work studied the inhibitory activity of andrographolide and andrograpanin, diterpenoids of the plant, on the rate of prostaglandin formation. Previous works have proven that andrographolide inhibited $\mathrm{PGE}_{2}$ production in LPS-induced human fibroblast cells. This study was performed by measuring the absorbance of TMPD (tetramethyl-p-phenyldiamine) oxidized by andrographolide and andrograpanin. Acetosal was used as a control drug. The rate of $\mathrm{PGH}_{2}$ formations on either $\mathrm{COX}-1$ or COX2 was affected by andrographolide and andrograpanin. Andrographolide and andrograpanin interact longer with COX-1 than COX-2. Andrographolide shows weak inhibition on the rate of $\mathrm{PGH}_{2}$ formation, whilst andrograpanin might be further developed for potential antiinflammatory drugs.
\end{abstract}

Keywords: Andrographis paniculata, anti-inflammatory, COX, cyclooxygenase, prostaglandin

\section{Introduction}

Cyclooxygenase (COX) or prostaglandin $\mathrm{H}_{2}$ synthase (PGHS) is the enzyme that catalyzes the first two steps in the biosynthesis of prostaglandins from the substrate, arachidonic acid. These are the oxidation of arachidonic acid to the hydroperoxy endoperoxide,

$\mathrm{PGG}_{2}$, and its subsequent reduction to the hydroxy endoperoxide, $\mathrm{PGH}_{2}$. The $\mathrm{PGH}_{2}$ is transformed by a range of enzymes and nonenzymatic mechanisms into the primary prostanoids, $\mathrm{PGE}_{2}, \mathrm{PGF}_{2 \alpha}, \mathrm{PGD}_{2}, \mathrm{PGI}_{2}$, and $\mathrm{TXA}_{2} \cdot{ }^{1}$

Corresponding author: Jutti Levita, Department of Pharmacology and Clinical Pharmacy, Faculty of Pharmacy, Universitas Padjadjaran, Jatinangor, West Java, Indonesia. Email: jutti.levita@unpad.ac.id

Received: 3 Oktober 2016. Revised: 19 November 2016. Published: 1 December 2016. 
The catalytic domain of COX constitutes the majority of the COX monomer and the site of substrate and NSAID binding. The entrance to the COX active site occurs at the base of the membrane binding domain and leads to a long hydrophobic channel that extends deep into the interior of the catalytic domain. ${ }^{2}$

The main reason for classifying COX-1 and COX-2 as physiological and pathological, respectively, is that COX-2 is only expressed when it is induced by stimuli and therefore, it is associated with inflammation. NSAIDs work by inhibiting both COX isoforms, thus the conversion of arachidonic acid into prostaglandin is disturbed. ${ }^{3}$ All NSAIDs in clinical use have been shown to inhibit COX, leading to a marked reduction in PG synthesis. The inhibition by aspirin is due to irreversible acetylation of the cyclooxygenase component of COX. In contrast, NSAIDs like indomethacin or ibuprofen inhibit COX reversibly by competing with the substrate, arachidonic acid, for the active site of the enzyme. ${ }^{1}$

COX-2 is a very important pharmaceutical target for the treatment of debilitating diseases like rheumatoid arthritis and osteoarthritis and as a preventative agent for colon cancer. However, important questions remain concerning the benefit-risk profiles of traditional NSAIDs, the diaryl heterocycle class of COX-2 selective inhibitors and structurally distinct inhibitors like lumiracoxib (2-[(2-chloro-6-fluorophenyl) amino]-5-methylphenyl)acetic acid) that are also selective for COX $-2{ }^{2}$

Selective inhibition of COX-2 promises to provide NSAIDs with increased safety and has already become a purposeful approach. A publication by Stubanus and colleague provides evidence suggesting that COX-2 inhibitors impair renal function and cause sodium retention in patients with mild preexisting renal failure and presumably also in some elderly patients with volume depletion. ${ }^{4}$

Therefore a bioresources-based medication is an interesting choice for safer intention. In Indonesia, Andrographis paniculata (A. paniculata), is empirically used to reduce inflammation by consuming the herb tea of this plant. Andrographolide and andrograpanin are lactone diterpenoids contained in this plant.

This work studied the inhibitory activity of andrographolide and andrograpanin on the rate of prostaglandin formation. Previous works have proven that andrographolide inhibited $\mathrm{PGE}_{2}$ production in LPS-induced human fibroblast cells. ${ }^{5}$

\section{Methods}

Instruments and glasswares

96-well plate (Cayman Chemical), freeze dryer (Telstar), micropipette (Socorex), microplate reader (MRX TC revelation), Eppendorf tubes, thermometer, digital analytical balance (Sartorius), vortex mixer (VM-300), and analytical glasswares.

\section{Chemicals}

Andrographolide CAS 5508-58-7 (Sigma Aldrich) and andrograpanin ASB-00001754010 (Chromadex). Chemicals are double distilled water (IPHA Laboratories), amyl alcohol (Agung Menara Abadi), ammonia (Agung Menara Abadi), hydrochloric acid (Agung Menara Abadi), acetylsalicylic acid (Bratachem), Colorimetric COX inhibitor screening assay kit No. 701050 (Cayman Chemical).

Inhibition of the rate of PGH2 formation by andrographolide and andrograpanin

A volume of $150 \mu 1$ of assay buffer, $10 \mu 1$ of heme and $7 \mu$ l of enzyme (either COX-1 

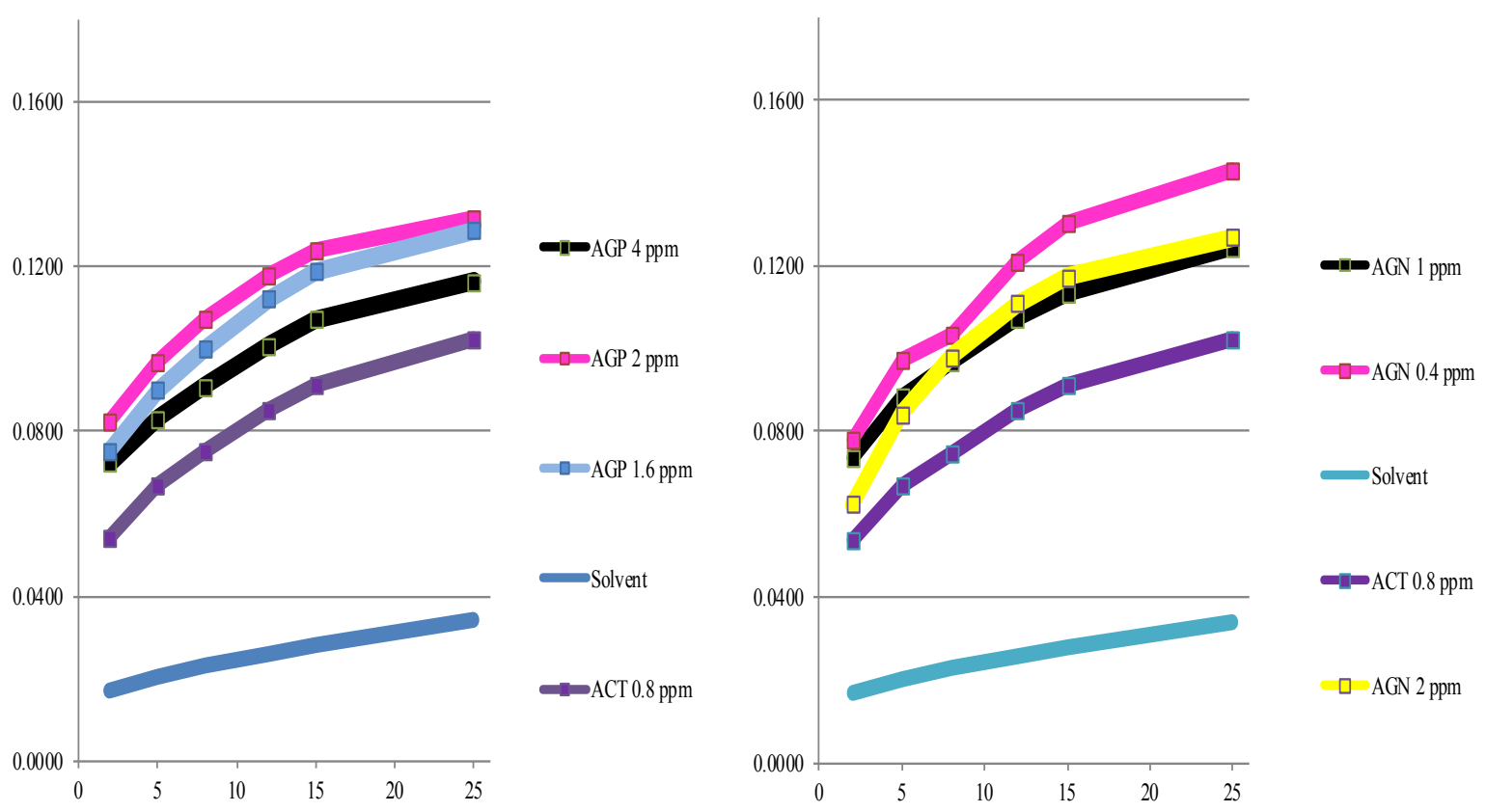

Figure 1. Andrographolide (left) and andrograpanin (right) inhibit the rate of PGH2 formation on COX-1

or COX-2) were added into each inhibitor well, followed by the addition of $20 \mu \mathrm{l}$ of andrographolide (AGP) or andrograpanin (AGN). The plate was stirred and incubated for 5 minutes at $25^{\circ} \mathrm{C}$. A volume of 15 $\mu 1$ of colorimetric substrate solution was added to all wells, followed by $20 \mu 1$ of arachidonic acid. The plate was stirred and incubated precisely for 2 minutes at $25^{\circ} \mathrm{C}$. The absorbance was measured at $590 \mathrm{~nm}$ in 5 minutes interval.

\section{Results and Discussion}

Inhibition of the rate of $\mathrm{PGH}_{2}$ formation was performed in vitro using Colorimetric COX Inhibitor Screening Assay Kit No. 705010 (Cayman Chemical Company). The basic principle of this kit is the oxidation reaction of the TMPD due to the peroxidase activity of the heme, thus causing the TMPD to release one electron to form a colored compound which absorbs at a wavelength of $\lambda 590 \mathrm{~nm} .{ }^{6}$ Higher catalysis activity of COX on arachidonic acid, resulted more oxidized
TMPD, thus increasing the absorbance.

In Figure 1, we observed that $\mathrm{PGH}_{2}$ on $\mathrm{COX}$ 1 was slowly produced as proven by the flat slope of the curve (during measuring time the absorbance values of oxidized TMPD were still low). This means that on COX1 , both compounds shows a higher affinity thus the substrate arachidonic acid reacts slower with the enzyme (in the performing the assay procedure, the arachidonic acid and TMPD were added after the enzyme was preincubated with the extracts).

On COX-2, the rate of $\mathrm{PGH}_{2}$ formation is faster (at 5 minutes, the absorbance of oxidized TMPD has already reached higher values). This also applies for acetosal whereby the rate of formation of prostaglandin with COX-1 is slower than with COX-2. AGP inhibits weakly whilst AGN $2 \mu \mathrm{g} / 1$ shows similar inhibition strength as acetosal (ACT) (Figure 2). 

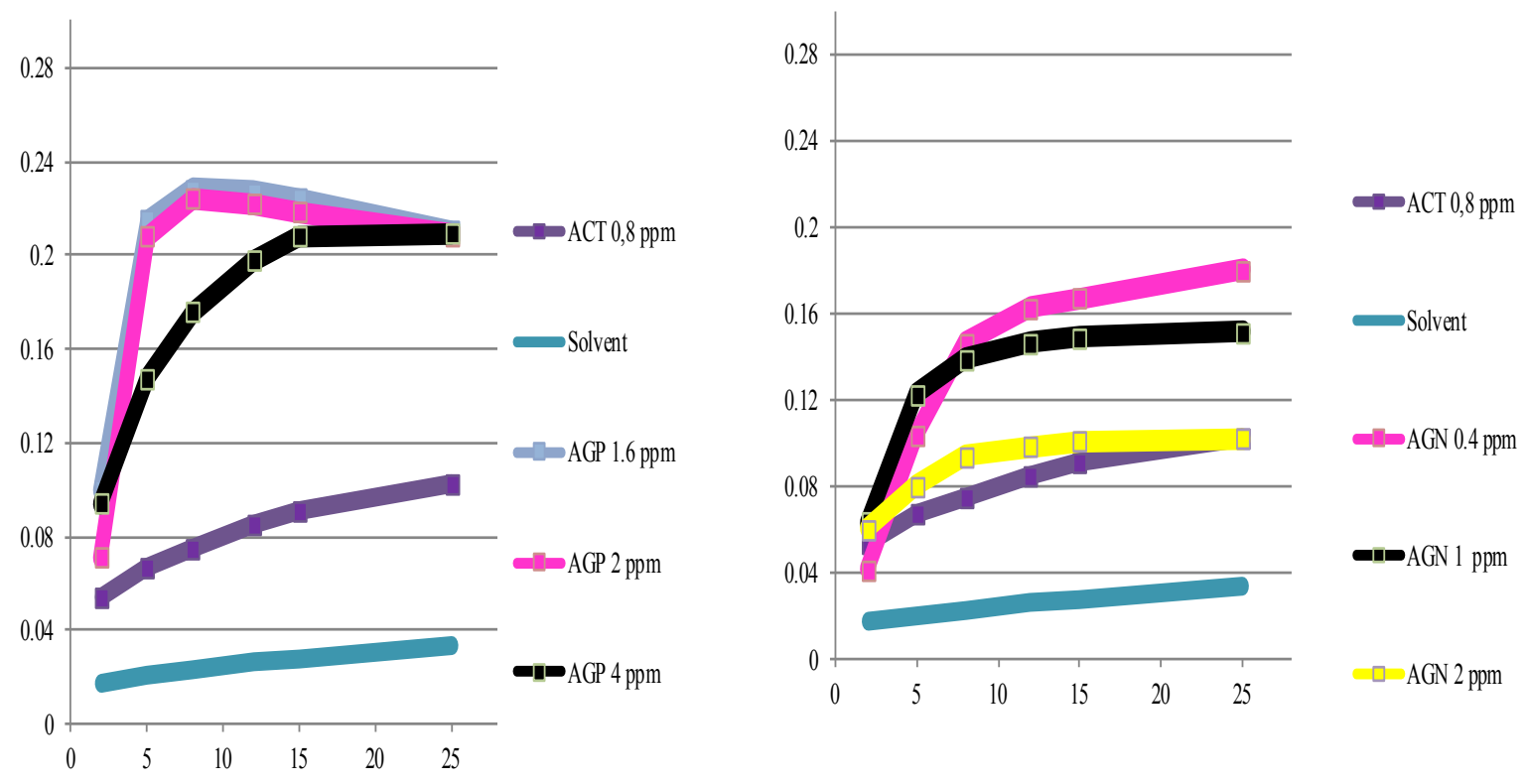

Figure 2. Andrographolide (left) and andrograpanin(right) inhibit the rate of $\mathrm{PGH} 2$ formation on $\mathrm{COX}-2$

The pattern of the curves could be explained by correlating it with the biosynthesis of prostaglandins (PGs). In the first step of biosynthesis of PGs, the substrate, arachidonic acid, has to react with COX enzyme and forms enzyme-substrate complex. This reaction takes place in the catalytic site of COX. In the second step, a conformational change occurs in the enzyme-substrate complex to enclose the substrate tightly in the enzyme to form the product. The enzyme then relaxes and releases the product. It could be seen that the amount of product increases with time until a plateau is reached (Figure 3).

As in the case of the interaction of a substrate with an enzyme, an inhibitor could also form a complex with an enzyme. The equilibrium constant, $\mathrm{Ki}\left(k_{2} / k_{1}\right)$ is a dissociation constant for cleavaging the enzyme-inhibitor

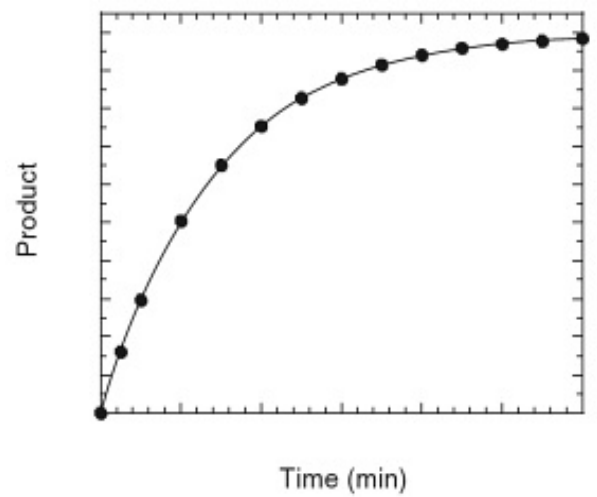

(b)

Figure 3. (a) Reaction of enzyme and substrate ${ }^{8}$; (b) Curve of product against time 
complex, therefore the smaller the Ki value for inhibitor, the more potent the inhibitor is. ${ }^{7}$ When inhibitor binds at the active site, the location where the substrate binds, then it is defined as a competitive inhibitor. Formation of the enzyme-inhibitor complex prevents the binding of the substrate to the enzyme, therefore blocks the catalytic conversion of the substrate, in this case is arachidonic acid, to product, which is $\mathrm{PGH}_{2}{ }^{9}$

The structural requirements for the timedependent inhibition of prostaglandin biosynthesis by different anti-inflammatory drugs were first evaluated by Rome and Lands, who studied ibuprofen, mefenamic acid, and flurbiprofen. A kinetic model was developed to explain their ohs ations in which there is an initial repid, reversible binding of the inhibitor to the enzyme characterized by a dissociation constant, $K_{1}$, followed by an essentially irreversible time-dependent change in the enzyme-inhibitor complex characterized by the rate constant. ${ }^{10-12}$<smiles>[Y][Ca][Ca]</smiles>

\section{Conclusion}

In our work, both AGP and AGN could inhibit the rate of $\mathrm{PGH}_{2}$ formation, therefore they might be potential as anti-inflammatory phytomedicines. Their anti-inflammatory activity are weaker than acetosal.

\section{References}

1. Ricciotti E, Fitz GA. Prostaglandins and inflammation. Arteriosclerosis, thrombosis, and vascular biology. 2011;31(5):986-1000.

2. Hinz B, Brune K. Paracetamol and cyclooxygenase inhibition: is there a cause for concern?. Annual Rheumatic Diseases. 2012:71;20-25.

3. Wang Z, Chen J, Liu J. COX2 inhibitors and gastric cancer.
Gastroenterology Research and Practice. 2014;2014:132320.

4. Kim GH. Renal effects of prostaglandins and cyclooxygenase-2 inhibitors. Electrolytes and Blood Pressure. 2008;6(1):35-41.

5. Levita J, Nawawi A, Mutalib A, et al. Andrographolide inhibits COX-2 expression in human fibroblast cells due to its interaction with arginine and histidine in cyclooxygenase site. Journal of Applied Science. 2010;10(14):14811484

6. Cayman Chemical Company. 2013. COX colorimetric inhibitor screening assay kit. Item No. 701050, Cayman Chemical Company, USA.

7. Chen C, Joo JC, Brown G, et al. Structure-based mutational studies of substrate inhibition of betaine aldehyde dehydrogenase from Staphylococcus aureus. Applied and Environmental Microbiology. 2014;80(13):3992-4002.

8. Dash R, Uddin MMN, Hosen SMZ. Molecular docking analysis of known flavonoids as duel COX-2 inhibitors in the context of cancer. Bioinformation. 2015;11(12):543-549.

9. Reddy KK, Vidya Rajan VK, Gupta A, et al. Exploration of binding site pattern in arachidonic acid metabolizing enzymes, cyclooxygenases and lipoxygenases. BMC Research Notes. 2015;8:152.

10. Zarghi A, Arfaei S. Selective COX-2 inhibitors: a review of their structureactivity relationships. Iranian Journal of Pharmaceutical Research. 2011;10(4):655-683.

11. Meek IL, van de Laar MAFJ, Vonkeman HE. Non-steroidal anti-inflammatory drugs: an overview of cardiovascular risks. Pharmaceuticals. 2010;3(7):21462162. 